\title{
Non-radiative transitions in metal-free octaethylporphyrin and 2- nitrofluorene donor-acceptor system
}

\author{
Mihir Ghosh ${ }^{a, \dagger, *}$, Shivraj ${ }^{b}$, B. Siddlingeshwar ${ }^{b}$, Anup Thomas ${ }^{c}$, Subrata Sinha $^{\text {a }}$ \\ ${ }^{a}$ Integrated Science Education and Research Centre, Siksha-Bhavana, Visva-Bharati, Santiniketan - 731 235, India \\ ${ }^{b}$ Department of Physics, M S Ramaiah Institute of Technology, Bengaluru, India \\ ${ }^{c}$ Center for Computational Research in Clean Energy Technologies, Sree Chitra Thirunal College of Engineering, \\ Pappanamcode, Trivandrum, India
}

\begin{abstract}
Photosynthetic reaction centre functions through non-covalent incorporation into a well-defined transmembrane proteins. In the context of exploring photoinduced electron transfer (PET) in non-covalent donor-acceptor systems, we have investigated electron transfer from metal-free octaethylporphyrin (OEP) donor to 2-nitrofluorene (2NF) acceptor in acetonitrile, a polar solvent. Steady-state and time-resolved emission spectroscopic studies in conjunction with density functional theory (DFT) calculations were employed to explore the electron transfer process. Quenching of the fluorescence emission intensity as well as fluorescence lifetime of the OEP upon excitation at the Q band of OEP at $300 \mathrm{~K}$, is attributed to the PET from OEP to 2NF. Our DFT [wB97XD functional and 6-31G $(\mathrm{d}, \mathrm{p})$ basis set] calculations also support the interaction between donor and acceptor and also reveals the co-facial $\pi-\pi$ interaction energy of -24.6 $\mathrm{kcal} / \mathrm{mol}$ with intermolecular distance less than $4 \AA$ A. Our results are expected to shed light on PET in noncovalent donor acceptor systems.
\end{abstract}

Keywords: Photoinduced electron transfer, Marcus theory, fluorescence quenching, Density functional theory.

\footnotetext{
*Corresponding author e-mail: mihir.chem86@gmail.com

${ }^{\dagger}$ Present Address: Department of Organic Chemistry, Weizmann Institute of Science, Rehovot-76100, Israel
} 


\section{Introduction}

The complexity and significance of electron transfer reactions in nature, have drawn the attention of the researchers to study the fundamental chemistry of these progressions in basic model systems. Therefore, a long-term aim of the researchers is to develop an understanding of photoinduced electron transfer (PET) reactions that is adequately advanced to enable one to design laboratory systems for the transformation of solar energy into chemical potential, as plants do efficiently during the photosynthesis. A crucial part of this research is to design the molecular systems, which consist of electron donors and acceptors that mimic the charge separation function of photosynthetic systems. However, till date, several synthetic models have been fabricated by variations in the electron transfer rate constants on donor-acceptor orientation, distance, electronic coupling and free energy of reaction [1].

As we know, during photosynthesis, flows of short-range electron transfer and energy transfer take place between well-organized organic pigments and some other cofactors [2]. The arrangement of the donor-acceptor couples in the photosynthetic reaction center is very simple and proficient via their noncovalent incorporation into well-defined transmembrane proteins. Therefore, control of electron transfer pathways in donor-acceptor systems by employing novel supramolecular concepts is significant not only to enrich our knowledge on the mechanistic details of the complex biological electron transfer processes [3-5], but also beneficial for fabricating molecular electronic devices [6,7] and sensors [8] and also in light energy harvesting systems. Supramolecular approach, both energetically and spatially, are the key factors to have control over the mechanism and the rate of energy transfer or electron transfer processes. The rich and wide absorptions range seen in porphyrinoid systems hold particular promise for increased absorptive cross sections and, thus, an effective use of the solar spectrum [9]. High electronic excitation energy of porphyrinoid systems $(>2.0 \mathrm{eV})$ influences a strong exergonic electron transfer that successively mediates the conversion between light and electrical/ chemical energy [10]. Porphyrins play a vital role in photosynthesis due to their strong absorption in the visible region, and the ease of adjusting their chemical structures. Porphyrins are wide class of materials, which are extensively studied for their role in electron transfer phenomenon in photosynthesis, dye sensitized solar cells (DSSCs), etc. In order to develop organic photovoltaic cells and artificial photosynthetic systems, photoinduced energy transfer and electron transfer processes have been widely studied in porphyrin based donor-acceptor (DA) molecular systems [11-16]. In our present study, we have selected octaethylporphyrin (OEP) as donor and 2-nitrofluorene (2NF) as an acceptor in acetonitrile polar solvent. The degree and mode of electron transfer from donor to the acceptor is a subject of intensive investigation. Different substitutions can be easily attached to porphyrin core to make the molecule more convenient in variety of material applications, including DSSCs. In literature, few reports are available on the use of metallo-octaethylporphyrins as donors in electron transfer studies with various acceptors [17-22]. In the present investigation, fluorescence quenching of OEP is measured in the presence of the quencher $2 \mathrm{NF}$ to study possible photoinduced electron transfer processes in this donoracceptor system by evading the competitive singletsinglet energy transfer process. To the best of our knowledge, this is the first report of using metal-free porphyrin as electron donor on PET study in the non covalent system.

\section{Experimental Section}

The solute molecule octaethylporphyrin $(2,3,7,8,12,13,17,18$-octaethyl-21H,23H-porphyrine, OEP) and quencher 2-nitrofluorene (2NF) (Fig. 1) were purchased from Sigma-Aldrich and used as received.

The steady state absorption spectra of the solute were recorded by using JASCO V-650 absorption spectrophotometer at the ambient temperature $(300 \mathrm{~K})$ by using $1 \mathrm{~cm}$ path length rectangular quartz cuvette. Steadystate fluorescence 


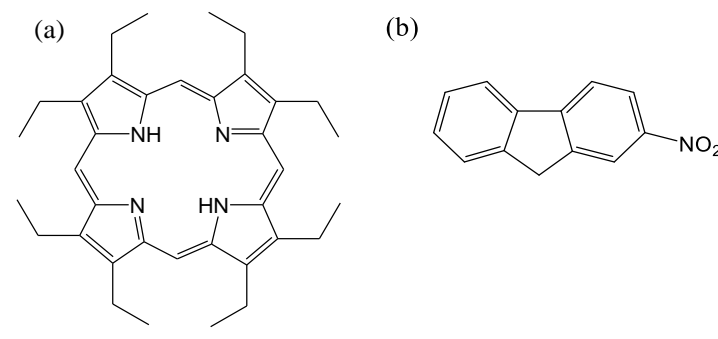

Figure 1. Chemical structures of (a) OEP (donor) and (b) 2NF (acceptor).

spectra of the samples were recorded by using JASCO FP6500 fluorescence spectrometer at $300 \mathrm{~K}$. The time-resolved emission measurements were carried out by time correlated single photon counting (TCSPC) spectrometer from IBH (UK). We used $1 \mathrm{MHz}$ repetition rate diode laser of $534 \mathrm{~nm}$ wavelength and PMT based detector (TBX4, IBH). The instrument response function (IRF $\sim 200 \mathrm{ps}$ ) of the TCSPC set-up was measured by collecting the scattered light from a $\mathrm{TiO}_{2}$ suspension in water and the decays were analyzed using IBH DAS-6 analysis software. The Durbin-Watson (DW) parameter, reduced $\chi^{2}$ and residuals were used to judge the perfection of the fit.

The theoretical calculations reported here were carried out using Gaussian09 electronic structure simulation software [23]. The gas phase ground state $\left(S^{0}\right)$ geometries of sensitizer (donor), quencher (acceptor) and sensitizerquencher (donor-acceptor) complex are found out by optimizing the guessed structures using long range corrected wB97XD DFT method coupled with a moderate 6-31G (d,p) basis set. Frequency calculations were also carried out to make sure that the computed geometries are indeed minima in the potential energy surface. Frontier molecular orbital (FMO) eigenvalues and their electron density distributions were obtained with B3LYP/6-31G (d, p) /wB97XD/6-31G (d,p) method [24-26]. Singlet excited states were calculated using the TDDFT [wB97XD/6-31G (d,p)] method.

\section{Results and Discussion}

\subsection{Steady state experimental studies:}

Figure 2 shows the absorption spectra of OEP and $2 \mathrm{NF}$ in polar solvent acetonitrile. The absorption spectra of OEP showed two bands; one is an intense band called $\mathrm{S}_{2}$ band or B band or Soret band, which appeared at $\lambda_{\max }=393$ $\mathrm{nm}$, and the other one is a very weak band called $\mathrm{S}_{1}$ band or $\mathrm{Q}$ band, which appeared at $\lambda_{\max }=496 \mathrm{~nm}, 528 \mathrm{~nm}, 564 \mathrm{~nm}$ and $618 \mathrm{~nm}$.

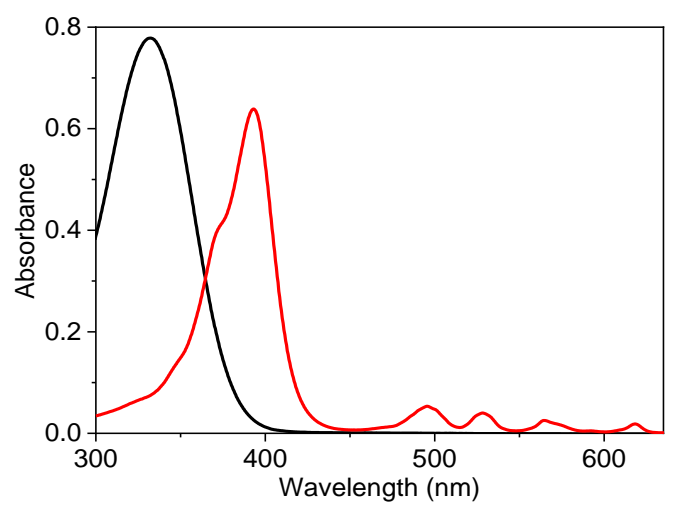

Figure 2. Steady state absorption spectra of OEP $\left(\right.$ Conc. $=3.9 \times 10^{-}$ ${ }^{6} \mathrm{~mol} / \mathrm{L}$, red), and $2 \mathrm{NF}$ (Conc. $=4.4 \times 10^{-5} \mathrm{~mol} / \mathrm{L}$, black) in $\mathrm{ACN}$ at $300 \mathrm{~K}$.

The absorption spectra of $2 \mathrm{NF}$ showed a peak at 332 $\mathrm{nm}$ due to $\mathrm{S}_{0} \rightarrow \mathrm{S}_{1}$ transition. These are known features of the present donor and acceptor molecules [27,28]. It is seen that in our present study, there was no ground state complex formation, when OEP and $2 \mathrm{NF}$ were mixed together in the solvent $\mathrm{ACN}$, even at high concentrations of the quencher $(2 \mathrm{NF})$.

Figure 3 shows the steady state fluorescence intensity curve of the donor OEP in presence of the acceptor $2 \mathrm{NF}(\mathrm{mol} / \mathrm{L})$ with different concentrations in ACN solvent. The self-quenching effects were minimized by measuring the fluorescence intensity of porphyrin in very dilute solutions $\left(\sim 10^{-6} \mathrm{~mol} / \mathrm{L}\right)$ [29]. The donor OEP molecule was excited at $564 \mathrm{~nm}$, where 2NF has negligible absorbance (Fig. 2). Furthermore, the OEP emission spectra and 2NF absorption spectra showed very low overlapping; thus the prospect of the radiative energy transfer or secondary inner filter effect is very less. Conversely, the appreciable quenching of the steady state emission of donors can be seen, when the concentration of $2 \mathrm{NF}\left(\sim 10^{-2}-10^{-3} \mathrm{~mol} / \mathrm{L}\right)$ is quite high. Yet, $2 \mathrm{NF}$ does not show any fluorescence band, when excited around $564 \mathrm{~nm}$, even at very high concentration. The inner filter effects (primary and secondary) by $2 \mathrm{NF}$ on the fluorescence of the porphyrins cannot be avoided entirely, exclusively in the lower wavelength region of fluorescence emission spectra. Hence, the steady state fluorescence spectra of the OEP in presence of $2 \mathrm{NF}$ were improved from the inner filter effect using the equation 1 [30].

$$
f_{\text {corrected }}=f_{\text {observed }} \text { antilog }\left(\frac{O D_{e x}+O D_{e m}}{2}\right)
$$

Where $\mathrm{OD}_{\mathrm{ex}}$ and $\mathrm{OD}_{\mathrm{em}}$ are the optical densities of $2 \mathrm{NF}$ at the excitation and emission wavelengths, respectively. 


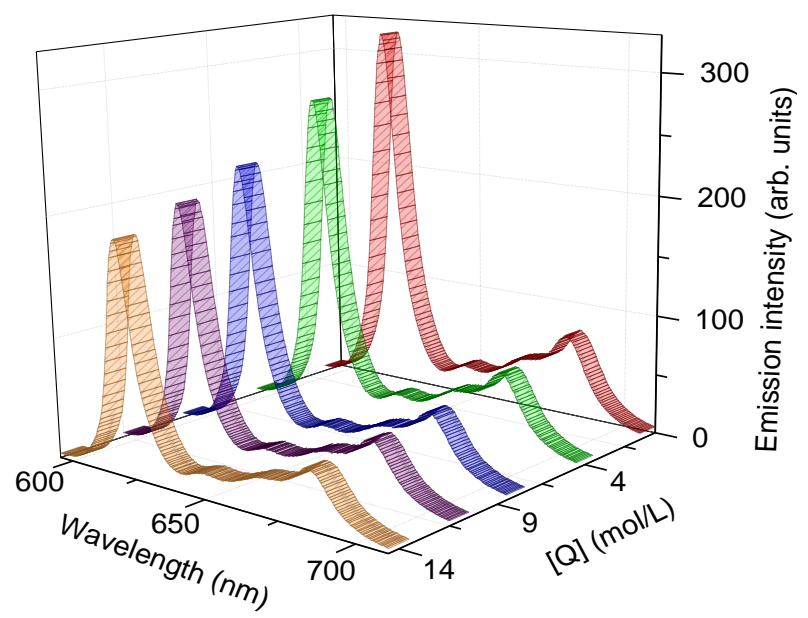

Figure 3. Steady state photoluminescence spectra of a mixture of OEP (concentration $=3.9 \times 10^{-6} \mathrm{~mol} / \mathrm{L}$ ) and $2 \mathrm{NF}$ in $\mathrm{ACN}$ liquid solution at $300 \mathrm{~K}\left(\lambda_{\mathrm{ex}}=564 \mathrm{~nm}\right)$. Concentration of $2 \mathrm{NF}(\mathrm{mol} / \mathrm{L})$ : (0) 0 ; (4) $2.1 \times 10^{-3}$ (8) $4.3 \times 10^{-3}$ (11) $5.8 \times 10^{-3}(14) 6.9 \times 10^{-3}$. All the spectra are modified from inner filter effect. (all the spectra are shown in supporting figure $\mathrm{S} 1$ ).

As anticipated, the modified fluorescence emission intensities of porphyrin accompanying $2 \mathrm{NF}$ are found to be marginally higher than the equivalent observed fluorescence emission intensities. However, figure 3 is based on the modified emission intensities of OEP in presence of acceptor2NF.

\subsection{Time-resolved studies:}

Table 1 shows the fluorescence lifetimes of OEP without and with $2 \mathrm{NF}$ in ACN solvent, which is found from the singleexponential fit of the decay curves. Table 1 and Fig. 4 show quenching of the fluorescence lifetime of OEP with regular addition of $2 \mathrm{NF}$.

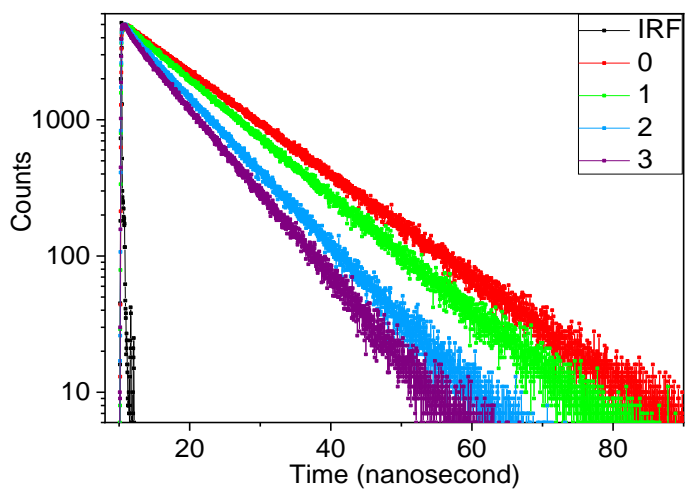

Figure 4. Fluorescence decay curve of OEP (concentration = $\left.4.0 \times 10^{-6} \mathrm{~mol} / \mathrm{L}\right)$ in presence of $2 \mathrm{NF}$ in $\mathrm{ACN}$ at $300 \mathrm{~K}\left(\lambda_{\mathrm{ex}}=534 \mathrm{~nm}\right.$, $\left.\lambda_{\text {emi }}=620 \mathrm{~nm}\right)$. Concentration of $2 \mathrm{NF}(\mathrm{mol} / \mathrm{L}):(0) 0$ (red); (1) $1.7 \times 10^{-3}$ (green); (2) $4.9 \times 10^{-3}$ (skyblue); (3) $6.9 \times 10^{-3}$ (purple). Black line represents IRF.

\begin{tabular}{|l|l|l|l|l|}
\hline $\begin{array}{l}\text { Concentration of } \\
2 \mathrm{NF}(\mathrm{mol} / \mathrm{L})\end{array}$ & 0 & $1.7 \times 10^{-3}$ & $4.9 \times 10^{-3}$ & $6.9 \times 10^{-3}$ \\
\hline$\tau(\mathrm{ns})$ & 11.45 & 10.01 & 7.96 & 7.03 \\
\hline
\end{tabular}

Table 1. Fluorescence lifetimes of OEP (concentration $=4.0 \times 10^{-6}$ $\mathrm{mol} / \mathrm{L})$ in absence and in presence of $2 \mathrm{NF}$ in $\mathrm{ACN}$ at $300 \mathrm{~K}\left(\lambda_{\mathrm{ex}}=\right.$ $\left.534 \mathrm{~nm}, \lambda_{\text {emi }}=620 \mathrm{~nm}\right)$.

\subsection{Fluorescence quenching rate:}

We observed that steady state fluorescence quenching follows the simple linear Stern-Volmer (SV) relation very well (Eq. (2) [30],

$$
\frac{f_{0}}{f}=1+K_{S V}[Q]
$$

Where $f_{0}$ and $f$ is the relative fluorescence emission intensities of the OEP donor without and with the quencher (2NF) concentration [Q], respectively. $\mathrm{K}_{\mathrm{SV}}\left(=\mathrm{k}_{\mathrm{q}} \tau_{\mathrm{o}}\right)$ is the Stern-Volmer constant, where $\mathrm{k}_{\mathrm{q}}$ is the second-order bimolecular fluorescence quenching rate constant and $\tau_{\mathrm{o}}$ is the fluorescence lifetime of the OEP in absence of the 2NF. The value $\mathrm{K}_{\mathrm{SV}}$ for OEP-2NF was obtained from the slope of the linear SV plot, which is $87.61 \mathrm{~L} / \mathrm{mol}$ form figure 5 . The value of $\mathrm{k}_{\mathrm{q}}$ is $7.65 \times 10^{9} \mathrm{~L} /(\mathrm{mol}-\mathrm{s})$ for OEP-2NF system obtained from $\mathrm{K}_{\mathrm{sv}}$ and $\tau_{\mathrm{o}}$. Hence, the calculated $\mathrm{K}_{\mathrm{sv}}$ value is slightly less than that of the second-order diffusioncontrolled rate constant $\left[1.9 \times 10^{10} \mathrm{~L} /(\mathrm{mol}-\mathrm{s})\right]$ in $\mathrm{ACN}$ solvent.

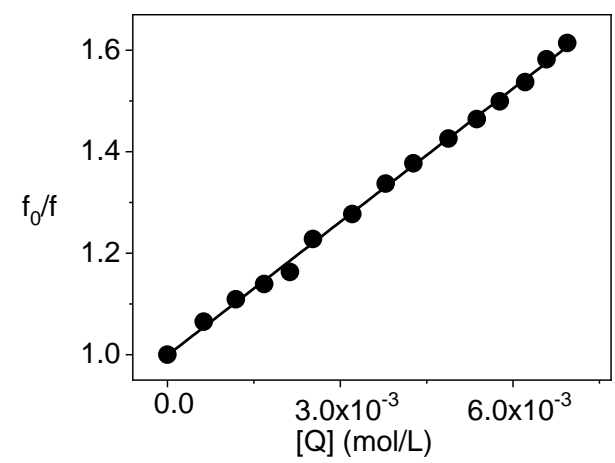

Figure 5. Stern-Volmer plot from the steady state fluorescence emission of OEP in presence of $2 \mathrm{NF}$ in $\mathrm{ACN}$ at $300 \mathrm{~K}\left(\lambda_{\mathrm{ex}}=564\right.$ $\mathrm{nm})$ obtained from figure 4.

This indicates the possibility of photoinduced electron transfer in the present donor-acceptor system. 


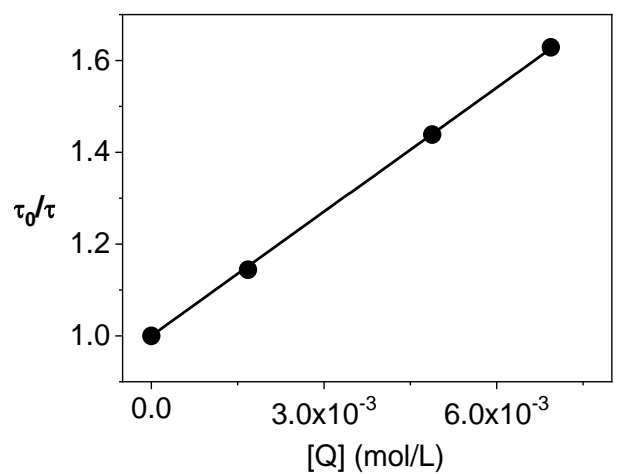

Figure 6. Stern-Volmer plot form fluorescence lifetime values of OEP in presence of $2 \mathrm{NF}$ in $\mathrm{ACN}$ at $300 \mathrm{~K}\left(\lambda_{\mathrm{ex}}=534 \mathrm{~nm}, \lambda_{\mathrm{emi}}=620\right.$ $\mathrm{nm})$.

As already discussed above, there is no intersecting area between the steady state emission spectra of the donor and absorption spectra of acceptor; hence, we can disregard the possibility of singlet-singlet energy transfer from the singlet excited OEP molecules to the ground state 2NF molecules. Fluorescence quenching data are obtained from the lifetime measurements of OEP by fitting the linear SV relation (Eq. 3) obtained from Fig. 4.

$$
\frac{\tau_{0}}{\tau}=1+K_{S V}[Q]
$$

Where $\tau_{0}$ and $\tau$ are the fluorescence lifetimes of the porphyrin without and with the quencher $2 \mathrm{NF}$, respectively. The value of $\mathrm{k}_{\mathrm{q}}$ is calculated from the slope of the linear plot (Figure 6), which is $7.94 \times 10^{9} \mathrm{~L} /(\mathrm{mol}-\mathrm{s})$ for the OEP-2NF system. The calculated value of $\mathrm{k}_{\mathrm{q}}$ is found to be again to some extent less than that of the diffusion controlled limit $\left[1.9 \times 10^{10} \mathrm{~L} /(\mathrm{mol}-\mathrm{s})\right]$ in ACN solvent. However, there could be the error limit for the steady state experiments of the order of $\pm 20 \%$ (approx.), whereas, the error limit for the life time measurements is of the order of $\pm 5 \%$ (approx.). Therefore, the time-resolved fluorescence quenching data are expected to specify the exact nature of the fluorescence quenching of the OEP molecule accompanied by $2 \mathrm{NF}$. Hence, steady-state and time-resolved measurements indicate the prospect of PET in OEP-2NF system in the ACN liquid medium.

\subsection{Photoinduced electron transfer:}

The first-order ET rate constant $\left(k_{E T}\right)$ is calculated from the Arrhenius equation.

$$
k_{E T}=A e^{\frac{-\Delta G^{*}}{k_{B} T}}
$$

According to Rehm and Weller, we treat ' $A$ ' is as an effective solution phase collision frequency, therefore, $\mathrm{A}=$ $1 \times 10^{11} \mathrm{~s}^{-1}[31]$. According to Marcus outer-sphere electron transfer theory, activation energy $\Delta \mathrm{G}^{*}$ is represented by equation 5 [32].

$$
\Delta G^{*}=\frac{\left(\Delta G^{0}+\lambda\right)^{2}}{4 \lambda}
$$

Where, $\Delta \mathrm{G}^{0}$ is the Gibbs free energy change and $\lambda$ is the nuclear reorganization energy associated with the electron transfer reaction.

According to the Rehm-Weller relation [33], $\Delta \mathrm{G}^{0}$ is given by the following equation.

$$
\Delta G^{0}=E_{1 / 2}^{o x}\left(\frac{D}{D^{+}}\right)-E_{1 / 2}^{r e d}\left(\frac{A^{-}}{A}\right)-E_{0,0}^{*}-\frac{e^{2}}{4 \pi \varepsilon_{0} \varepsilon_{S} R}
$$

Where, $E_{1 / 2}^{o x}\left(\mathrm{D} / \mathrm{D}^{+}\right)$and $E_{1 / 2}^{r e d}\left(\mathrm{~A}^{-} / \mathrm{A}\right)$ are half-wave oxidation potential of the donor and half-wave reduction potential of the acceptor, respectively. $E_{0,0}^{*}$ is the $(0,0)$ energy of the donor molecule. A wavelength of $564 \mathrm{~nm}$ was considered for the excitation of steady state measurement, while, a wavelength of $534 \mathrm{~nm}$ was considered for time-resolved measurements, for the porphyrin in the present investigation. Nevertheless, in either case (steady state or time-resolved measurements), porphyrin molecule excited to higher vibrational levels of the $S_{1}$ state suffers fast, non-radiative vibrational relaxation to the $0^{\text {th }}$ vibrational level of the $S_{1}$ state. Consequently, electron transfer takes place between the D-A pairs. This fact validates the use of $(0,0)$ energy of the fluorophore (2.006 eV corresponds to $618 \mathrm{~nm}$ for OEP, Fig. 2) in Eq. 6. The last term on the RHS of Eq. 6 is the Coulomb term, where ' $R$ ' stands for the distance between the oxidized donor and the reduced acceptor. The value of $R$ is generally considered as the sum of the radii of oxidized donor and reduced acceptor. Hence, the radii of the donor OEP and acceptor $2 \mathrm{NF}$ were taken as $7.2 \AA$ and $5.1 \AA$, respectively. The radii values were computed using a MOPAC-CI $(6 \times 6)$ [Version 5 package with AMI Hamiltonian] for the OEP and 2NF molecules in their ground states. Further, in Eq. 6, 'e' is the charge of an electron, ' $\varepsilon_{0}$ ' is the vacuum permittivity and ' $\varepsilon_{\mathrm{s}}$ ' is the dielectric constant $\left(\varepsilon_{\mathrm{s}}=37.5\right)$ and the Coulomb term is $0.03 \mathrm{eV}$ only for polar solvent ACN. The oxidation potential value of OEP is taken as $0.81 \mathrm{~V}$ [34], while $2 \mathrm{NF}$ possesses the reduction potential of about $-1.18 \mathrm{~V}$ [35]. Hence, the value of $\Delta \mathrm{G}^{0}$ comes out to be $-0.0472 \mathrm{eV}$ for OEP-2NF system in the ACN solvent. 
The obtained negative value of $\Delta \mathrm{G}^{0}\left(\Delta \mathrm{G}^{0}<0\right)$ indicates the existence of photoinduced electron transfer from the OEP to $2 \mathrm{NF}$ in $\mathrm{ACN}$ upon excitation of the former molecules is exergonic and therefore energetically feasible.

In Equation 5, $\lambda$ is the nuclear reorganization energy associated with the electron transfer reaction and would be expressed by the summation of $\lambda_{\mathrm{i}}$ and $\lambda_{\mathrm{o}}$. $\lambda_{\mathrm{i}}$ is the innersphere reorganization energy originated from the intramolecular bond length and outer-sphere reorganization energy $\lambda_{0}$ is obtained from reorientation of the solvent molecules.

$$
\lambda=\lambda_{i}+\lambda_{0}
$$

$\lambda_{\mathrm{i}}$ can be calculated from the force constants for all the molecular vibrations in both the reactants and products. Though, a fixed value of $0.3 \mathrm{eV}$ is preferred for $\lambda_{\mathrm{i}}$. This value of $\lambda_{\mathrm{i}}$ has been used by many researchers in their articles as a characteristic value for aromatic D-A systems $[36,37,38]$. The value of $\lambda_{0}$ was calculated using the dielectric continuum model of two spherical reactants (Eq. 8) [39,40].

$$
\lambda_{0}=\frac{e^{2}}{4 \pi \varepsilon_{0}}\left[\frac{1}{\varepsilon_{o p}}-\frac{1}{\varepsilon_{S}}\right]\left[\frac{1}{2 r_{D}}+\frac{1}{2 r_{A}}-\frac{1}{R}\right]
$$

Where ' $\varepsilon_{o p}$ ' is the solvent refractive index (optical dielectric constant); $r_{D}$ and $r_{A}$ are the radii of the oxidized donor and reduced acceptor, respectively, and $\mathrm{R}=\left(\mathrm{r}_{\mathrm{D}}+\mathrm{r}_{\mathrm{A}}\right)$ (center to center distance between donor and acceptor molecules). $\lambda_{0}$ value calculated from the system we used is $0.624 \mathrm{eV}$. Consequently, the calculated value of the nuclear reorganization energy associated with the electron transfer reaction comes out to be $0.924 \mathrm{eV}$ for the $\mathrm{D}-\mathrm{A}$ system. Using the equation 5 we can calculate the activation energy for our system $(0.028 \mathrm{eV})$. Hence our calculated $\mathrm{k}_{\mathrm{ET}}$ value is $3.21 \times 10^{7} \mathrm{~s}^{-1}$ for OEP-2NF system in ACN solvent.

\subsection{Computational analysis:}

Computational DFT studies have been carried out to comprehend the intermolecular PET process. The ground state structures of the donor and acceptor were attained by gas phase geometry optimization process using wB97XD/6$31 \mathrm{G}(\mathrm{d}, \mathrm{p})$ method and the resulting optimized coordinates and the structures were presented in ESI (Figure S2 and S3). To study the interaction between donor and acceptor, various spatially oriented geometrical guesses of donor along with

\begin{tabular}{|c|c|c|c|c|}
\hline & $\begin{array}{l}\text { Electronic } \\
\text { Transition }\end{array}$ & $\begin{array}{l}\text { Absorption } \\
\text { energies } \\
(\mathrm{nm})\end{array}$ & $\mathrm{F}$ & \\
\hline \multirow[t]{5}{*}{ A } & $\mathrm{S}_{0}-\mathrm{S}_{1}$ & 309 & 0.00 & $\mathrm{H}-3 \rightarrow \mathrm{L} \quad 80 \% \quad \mathrm{H}-3 \rightarrow \mathrm{L}+2 \quad 12 \%$ \\
\hline & $\mathrm{S}_{0}-\mathrm{S}_{2}$ & 279 & 0.57 & $\mathrm{H} \rightarrow \mathrm{L} 88 \%$ \\
\hline & $\mathrm{S}_{0}-\mathrm{S}_{3}$ & 275 & 0.00 & $\mathrm{H}-6 \rightarrow \mathrm{L} \quad 81 \% \quad \mathrm{H}-6 \rightarrow \mathrm{L}+2 \quad 11 \%$ \\
\hline & $\mathrm{S}_{0}-\mathrm{S}_{4}$ & 259 & 0.03 & $\mathrm{H}-2 \rightarrow \mathrm{L} \quad 55 \% \quad \mathrm{H}-1 \rightarrow \mathrm{L} \quad 21 \% \quad \mathrm{H} \rightarrow \mathrm{L}+1 \quad 10 \%$ \\
\hline & $\mathrm{S}_{0}-\mathrm{S}_{5}$ & 309 & 0.00 & $\mathrm{H}-3 \rightarrow \mathrm{L} \quad 80 \% \quad \mathrm{H}-3 \rightarrow \mathrm{L}+2 \quad 12 \%$ \\
\hline \multirow[t]{5}{*}{ D } & $\mathrm{S}_{0}-\mathrm{S}_{1}$ & 584 & 0.01 & $\mathrm{H} \rightarrow \mathrm{L} 54 \% ; \mathrm{H}-1 \rightarrow \mathrm{L}+146 \%$ \\
\hline & $\mathrm{S}_{0}-\mathrm{S}_{2}$ & 530 & 0.02 & $\mathrm{H} \rightarrow \mathrm{L}+157 \% ; \mathrm{H}-1 \rightarrow \mathrm{L} 43 \%$ \\
\hline & $\mathrm{S}_{0}-\mathrm{S}_{3}$ & 363 & 0.78 & $\mathrm{H} \rightarrow \mathrm{L} 38 \% ; \mathrm{H}-1 \rightarrow \mathrm{L}+138 \%$ \\
\hline & $\mathrm{S}_{0}-\mathrm{S}_{4}$ & 344 & 1.31 & $\mathrm{H} \rightarrow \mathrm{L}+143 \% ; \mathrm{H}-1 \rightarrow \mathrm{L} 52 \%$ \\
\hline & $\mathrm{S}_{0}-\mathrm{S}_{5}$ & 333 & 0.00 & $\mathrm{H}-2 \rightarrow \mathrm{L}+189 \%$ \\
\hline \multirow[t]{5}{*}{$\begin{array}{l}\text { D-A } \\
\text { Complex }\end{array}$} & $\mathrm{S}_{0}-\mathrm{S}_{1}$ & 585 & 0.01 & $\begin{array}{l}\mathrm{H} \rightarrow \mathrm{L} 30 \% ; \quad \mathrm{H} \rightarrow \mathrm{L}+123 \% ; \mathrm{H}-1 \rightarrow \mathrm{L} 21 \% \mathrm{H}- \\
1 \rightarrow \mathrm{L}+125 \%\end{array}$ \\
\hline & $\mathrm{S}_{0}-\mathrm{S}_{2}$ & 534 & 0.02 & $\begin{array}{l}\mathrm{H} \rightarrow \mathrm{L} 27 \% ; \quad \mathrm{H} \rightarrow \mathrm{L}+132 \% ; \mathrm{H}-1 \rightarrow \mathrm{L} 23 \% \mathrm{H}- \\
1 \rightarrow \mathrm{L}+117 \%\end{array}$ \\
\hline & $S_{0}-S_{3}$ & 380 & 0.19 & $\mathrm{H} \rightarrow \mathrm{L}+2 \quad 59 \%$ \\
\hline & $\mathrm{S}_{0}-\mathrm{S}_{4}$ & 369 & 0.36 & $\mathrm{H} \rightarrow \mathrm{L}+2 \quad 39 \% ; \mathrm{H}-1 \rightarrow \mathrm{L} 16 \%$ \\
\hline & $\mathrm{S}_{0}-\mathrm{S}_{5}$ & 363 & 0.02 & $\mathrm{H}-1 \rightarrow \mathrm{L}+2 \quad 92 \%$ \\
\hline
\end{tabular}
acceptor was optimized at the same level of theory.

Table 2. Calculated electronic absorption energies (in $\mathrm{nm}$ ), oscillator strengths (f) and main configuration along with percentage contributions of first five excited states of acceptor A, donor $\mathbf{D}$ and donor- acceptor D-A complex calculated using TDDFT-wB97xD/6-31G(d,p). 


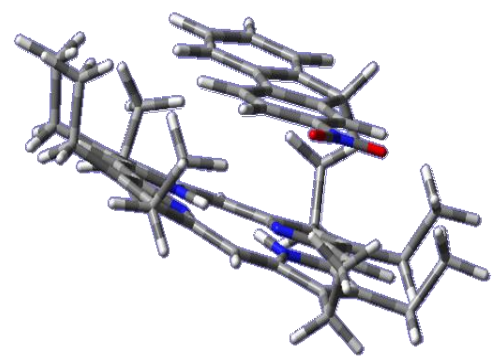

Figure 7 . The $\pi-\pi$ interacting D-A complex geometry predicted by wB97xD/6-31G(d,p) method.

Interestingly, a co-facial $\pi-\pi$ interaction between donor and acceptor with an interaction energy of $(-24.6 \mathrm{kcal} / \mathrm{mol})$ is obtained for the system studied here (Figure 7). The intermolecular distance is less than $4 \AA$. The FMO picture along with the energy level alignments of donor, acceptor and donor-acceptor system are shown in figure 8 . The HOMO and LUMO eigen value of the acceptor is lower than that of donor by about 1.59 and $0.34 \mathrm{eV}$, respectively. From the figure it is clearly visible that upon donor-acceptor complexation, the LUMO of the acceptor is destabilized due to orbital overlap between donor and acceptor.

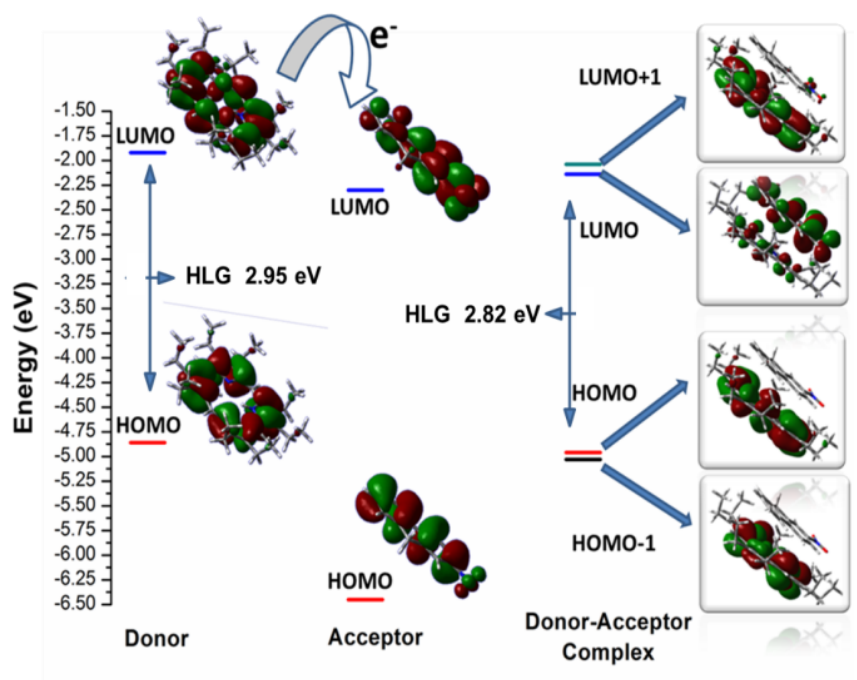

Figure 8: Molecular orbital diagrams of $\mathbf{D}, \mathbf{A}$ and $\mathbf{D}-\mathbf{A}$ complex obtained at B3LYP/6-31G(d,p)//wb97XD/6-31G(d,p).

For the donor-acceptor system the electron density distribution of HOMO and HOMO-1 is purely centered on donor moiety, whereas the LUMO is largely distributed on acceptor moiety and LUMO+1 on donor part. This offers an indirect evidence on the viability of photoinduced electron transfer from donor to acceptor. Fascinatingly, one could observe that the HOMO-LUMO gap (HLG) of the donor and HOMO-LUMO+1 gap $\left(\mathrm{HL}^{+1} \mathrm{G}\right)$ of donor and acceptor are almost equal in magnitudes.

In order to get more details on the fluorescence quenching in this studied system, we have calculated the lowest five excitation energies for the possible absorption of $\mathrm{UV} /$ visible light of acceptor, donor and donor-acceptor complex using TDDFT/wB97XD/6-31G(d,p) method (see table 2). The purpose of this study is not to accurately reproduce the magnitudes of experimentally observed results, but to establish the through space charge transfer upon excitation. We have selected wB97XD method, which is known to take care of the charge transfer excitations [41]. The trends in experimentally observed absorption wavelengths are correlating with the theoretically estimated excitation energies. It is interesting to see that TDDFT has predicted almost same absorption maxima values for the donor and the donor-acceptor complex. This is why we could not experimentally observe this strong coupling in the experimental spectra. It is in line with the fluorescence quenching predictions made by Korzdorfer et al. [42] in perylene-bisimide (donor)-triphenylamine (acceptor)

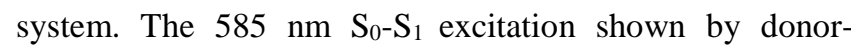
acceptor complex involves the configurations, both from LUMO and LUMO-1. Thus, we could clearly ascertain that fluorescence quenching in this type of system is due to charge transfer coupling caused by orbital overlap between the donor and acceptor.

\section{Conclusions}

We investigate photoinduced electron transfer (PET) from metal-free octaethylporphyrin (OEP) donor to 2nitrofluorene (2NF) acceptor in acetonitrile using steadystate and time-resolved emission spectroscopy in conjunction with density functional theory (DFT) calculations. The emission intensity as well as fluorescence lifetime of OEP is highly quenched at $300 \mathrm{~K}$ as we increase the quencher (2NF) concentration in the solution, which is attributed to the PET from OEP to 2NF due to excitation at $\mathrm{Q}$ band of OEP. From our corrected linear Stern-Volmer plot, we find good correlations between the second order bimolecular fluorescence quenching constants obtained from steady-state $\left(7.65 \times 10^{9} \mathrm{~L} / \mathrm{mol}-\mathrm{s}\right)$ and time-resolved $\left(7.94 \times 10^{9}\right.$ L/mol-s) studies. We have computed the lowest five excitation energies of the OEP, 2NF and OEP-2NF complex in the excited state. The donor and acceptor show co-facial $\pi-\pi$ interaction and the binding energy of the complex is 
computed to be $-24.6 \mathrm{kcal} / \mathrm{mol}$. Therefore, our experimental and quantum chemical studies clearly ascertain the fluorescence quenching of the OEP in the presence of $2 \mathrm{NF}$ is due to charge transfer coupling caused by OEP and $2 \mathrm{NF}$ molecular orbital overlap. This approach reveals an important feature for photoinduced electron transfer in noncovalent donor-acceptor system.

\section{Appendix A. Supporting information}

Supplementary data associated with this article can be found in the online version.

Acknowledgement: We would like to thank Dr. Ramprasad Misra in expert assistance in the preparation of the manuscript. 


\section{References}

[1] M. R. Wasielewski, Photoinduced electron transfer in supramolecular systems for artificial photosynthesis, Chem. Rev. 92 (1992) 435-461.

[2] J. Deisenhofer and J. R. Norris, The Photosynthetic Reaction Center, Ed. Academic Press, New York, 1993.

[3] R. A. Wheeler, Introduction to the Molecular Bioenergetics of Electron, Proton, and Energy Transfer; ACS Symposium Series: American Chemical Society, Washington, DC, 2004, Vol. 883, p-1.

[4] W. Leibl, P. Mathis, Electron Transfer in Photosynthesis; Series on Photoconversion of Solar Energy: 2004, Vol. 2, p 117.

[5] K. R. Rodgers, G. S. Lukat-Rodgers, Compr. Coord. Chem. II 8 (2004) 17-19.

[6] V. Balzani, F. Scandola, Supramolecular Chemistry, Ellis Horwood: New York, 1991.

[7] B. Schlicke, L. De Cola, P. Belser, V. Balzani, Rigid rod-like molecular wires of nanometric dimension. Electronic energy transfer from a napthyl to an anthracenyl unit connected by a 1,4-pentaphenylene spacer, Coord. Chem. Rev. 208 (2000) 267-275.

[8] T. W. Bell, N. M. Hext, Supramolecular optical chemosensors for organic analytes, Chem. Soc. Rev. 33 (2004) 589-598.

[9] K. M. Kadish, K. M. Smith, R. Guilard (Eds.), The Porphyrin Handbook, Academic Press, New York, PubMed, 1999.

[10] D. M. Guldi, Fullerene-porphyrin architectures; photosynthetic antenna and reaction center models, Chem. Soc. Rev. 31 (2002) 22-36.

[11] H. L. Cheng, Z. Huang, L. Wang, H. Meier, D. Cao, Synthesis and photovoltaic performance of the porphyrin based sensitizers with 2H-[1,2,3] triazolo [4,5-c]pyridine and benzotriazole as auxiliary acceptors, Dyes and Pigments. 137 (2017) 143-151.

[12] M. Ghosh, A. K. Mora, S. Nath, A. Hajra, P. H. Kumar, P. R. Bangal, S. Sinha, Photoinduced electron transfer from zinc tetraphenylporphyrin to 2-nitrofluorene in polar solvent acetonitrile, J. Photochem. Photobiol. A 306 (2015) 55-65.

[13] T. A. Reekie, M. Sekita, L. M. Urner, S. Bauroth, L.Ruhlmann, J. P. Gisselbrecht, C. Boudon, N. Trapp, T. Clark, D. M. Guldi, F. Diederich, Porphyrin Donor and Tunable Push-Pull Acceptor ConjugatesExperimental Investigation of Marcus Theory, Chem. Eur. J. 23 (2017) 6357- 6369.

[14] M. Ghosh, A. K. Mora, S. Nath, A. Hajra, S. Sinha, Photoinduced electron transfer in metallooctaethylporphyrin (donor)-2-nitrofluorene (acceptor) systems in polar acetonitrile liquid medium, J. Photochem. Photobiol. A 290 (2014) 94-100.

[15] A. Benitz, M. B. Thomas, F. D'Souza, Geometry-controlled photoinduced charge separation and recombination in a trans- $A_{2} B_{2}$-functionalized donor-acceptor conjugate composed of a multimodular zinc porphyrin and fullerene, Chem. Photo. Chem. 1 (2017) 17-25.

[16] M. Ghosh, B. Roy, K. Majhi, A. K. Mora, S. Nath, S. Sinha, Fluorescence quenching of 9cyanoanthracene by metallo-octaethylporphyrins in cyanobenzene, J. Porph. Phthalocyanines 19 (2015) 1063-1071.

[17] A. Ilani, M. Woodle, D. Mauzerall, Photoinduced electron transfer across lipid bilayers containing magnesium octaethylporphyrin, Photochem. Photobiol. 49 (1989) 673-679.

[18] K. Sun, D. Mauzerall, Fast photoinduced electron transfer from polyalkyl-to polyfluorometalloporphyrins in lipid bilayer membranes, J. Phys. Chem. B 102 (1998) 6440-6447.

[19] M. E. El-Khouly, M. Fujitsuka, O. Ito, Efficient photoinduced electron transfer between $C_{60} / C_{70}$ and zinc octaethylporphyrin studied by nanosecond laser photolysis method, J. Porphyr. Phthalocyanines 4 (2000) 591-598. 
[20] E.I. Zenkevich, D.S. Kilin, A. Willert, S.M. Bachilo, A.M. Shulga, U. Rempel, C. von Borczyskowski, Photoinduced electron transfer dynamics for self-assembled porphyrin arrays in solutions and films, Mol. Cryst. Liq. Cryst. 361 (2001) 83-88.

[21] M.E. El-Khouly, Y. Araki, M. Fujitsuka, O. Ito, Photoinduced electron transfer between metal octaethylporphyrins and fullerenes $\left(C_{60} / C_{70}\right)$ studied by laser flash photolysis: electron-mediating and hole-shifting cycles, Phys. Chem. Chem. Phys. 4 (2002) 3322-3329.

[22] D.I. Schuster, P. Cheng, P.D. Jarowski, D.M. Guldi, C. Luo, L. Echegoyen, S. Pyo, A.R. Holzwarth, S.E. Braslavsky, R.M. Williams, G. Klihm, Design, synthesis, and photophysical studies of a porphyrinfullerene dyad with parachute topology; charge recombination in the Marcus inverted region, J. Am. Chem. Soc. 126 (2004) 7257-7270.

[23] Gaussian 09, Revision D.01, M. J. Frisch, G. W. Trucks, H. B. Schlegel, G. E. Scuseria, M. A. Robb, J. R. Cheeseman, G. Scalmani, V. Barone, B. Mennucci, G. A. Petersson, H. Nakatsuji, M. Caricato, X. Li, H. P. Hratchian, A. F. Izmaylov, J. Bloino, G. Zheng, J. L. Sonnenberg, M. Hada, M. Ehara, K. Toyota, R. Fukuda, J. Hasegawa, M. Ishida, T. Nakajima, Y. Honda, O. Kitao, H. Nakai, T. Vreven, J. A. Montgomery, Jr., J. E. Peralta, F. Ogliaro, M. Bearpark, J. J. Heyd, E. Brothers, K. N. Kudin, V. N. Staroverov, T. Keith, R. Kobayashi, J. Normand, K. Raghavachari, A. Rendell, J. C. Burant, S. S. Iyengar, J. Tomasi, M. Cossi, N. Rega, J. M. Millam, M. Klene, J. E. Knox, J. B. Cross, V. Bakken, C. Adamo, J. Jaramillo, R. Gomperts, R. E.Stratmann, O. Yazyev, A. J. Austin, R. Cammi, C. Pomelli, J. W. Ochterski, R. L. Martin, K. Morokuma, V. G. Zakrzewski, G. A. Voth, P. Salvador, J. J. Dannenberg, S. Dapprich, A. D. Daniels, O. Farkas, J. B. Foresman, J. V. Ortiz, J. Cioslowski, and D. J. Fox, Gaussian, Inc., Wallingford CT, 2013.

[24] A. Thomas, K. Bhanuprakash, Comparative study of the semiconducting properties of benzothiadiazole and benzobis (thiadiazole) derivatives using computational techniques, Chem. Phys. Chem. 13 (2012) 597-605.

[25] M. Winkler, K. N. Houk, Nitrogen-rich oligoacenes: candidates for n-channel organic semiconductors, J. Am. Chem. Soc. 129 (2007) 1805-1815.

[26] A. Thomas, K. Srinivas, C. Prabhakar, K. Bhanuprakash, V. J. Rao, Estimation of the first excitation energy in diradicaloid croconate dyes having absorption in the near infra-red (NIR): A DFT and SFTDDFT study, Chem. Phys. Lett. 454 (2008) 36-41.

[27] S. Sinha, T. Ganguly, Investigations on the photophysical properties of 2-methylindole and 2methylindoline in various environments. Studies on the nature of non-radiative transitions in presence of the electron acceptor 2-nitrofluorene, J. Lumin. 79 (1998) 201-209.

[28] M. Ghosh, S. Sinha, Solvatochromic Stokes shift and determination of excited state dipole moments of free base and zinc octaethylporphyrin, Spectrochim. Act. Part A: Mol. and Biomol. Spec. 150 (2015) 959-965.

[29] M. Ghosh, S. Nath, A. Hajra, S. Sinha, Fluorescence self-quenching of tetraphenylporphyrin in liquid medium, J. Lumin. 141 (2013) 87-92.

[30] J. R. Lakowicz, Principles of Fluorescence Spectroscopy, 2nd ed., Kluwer Academic/Plenum Publishers, New York, 1999.

[31] J. Chen, T. Ho, C. Mou, Experimental investigation of excited-state electron-transfer reaction: effects of free energy and solvent on rates, J. Phys. Chem. 94 (1990) 2889-2896.

[32] R. A. Marcus, N. Sutin, Electron transfers in chemistry and biology, Biochim. Biophys. Acta 811 (1985) 265-322.

[33] D. Rehm, A. Weller, Kinetics of fluorescence quenching by electron and H-atom transfer, Isr. J. Chem. 8 (1970) 259-271.

[34] D. Dolphin (Eds.) The porphyrins V5: Physical Chemistry, Part3, Academic Press, 1978, p.142.

[35] S. Sinha, R. De, T. Ganguly, Electron Transfer Reactions in the Excited Singlet States of Dimethyl Substituted Phenol-2-Nitrofluorene Systems: Evidence for the Marcus Inverted Region and Concurrent Occurrence of Energy Transfer Processes, J. Phys. Chem. A 101 (1997) 2852-2858. 
[36] G.L. Closs, M.D. Johnson, J.R. Miller, P. Piotrowiack, A connection between intramolecular long-range electron, hole, and triplet energy transfers, J. Am. Chem. Soc. 111 (1989) 3751-3753.

[37] I.R. Gould, D. Ege, J.E. Moser, S. Farid, Efficiencies of photoinduced electron-transfer reactions: role of the Marcus inverted region in return electron transfer within geminate radical-ion pairs, J. Am. Chem. Soc. 112 (1990) 4290-4301.

[38] J.M. Warman, K.J. Smit, M.P. de Haas, S.A. Jonker, M.N. Paddon-Row, A.N. Oliver,J. Kroon, H. Oevering, J.W. Verhoeven, Long-distance charge recombination within rigid molecular assemblies in nondipolar solvents, J. Phys. Chem. 95 (1991) 1979-1987.

[39] R.A. Marcus, N. Sutin, Electron transfers in chemistry and biology, Biochim. Biophys. Acta 811 (1985) 265-273.

[40] R. A. Marcus, On the Theory of Oxidation-Reduction Reactions Involving Electron Transfer. I J. Chem. Phys. 24 (1956) 966-978.

[41] J.-D. Chai, M. Head-Gordon, Long-range corrected hybrid density functionals with damped atom-atom dispersion corrections, Phys. Chem. Chem. Phys. 10 (2008) 6615-6620.

[42] T. Körzdörfer, S. Tretiak, S. Kümmel, Fluorescence quenching in an organic donor-acceptor dyad: A first principles study, Chem. Phys. 131 (2009) 0343101-0343108. 


\section{Supporting Information:}

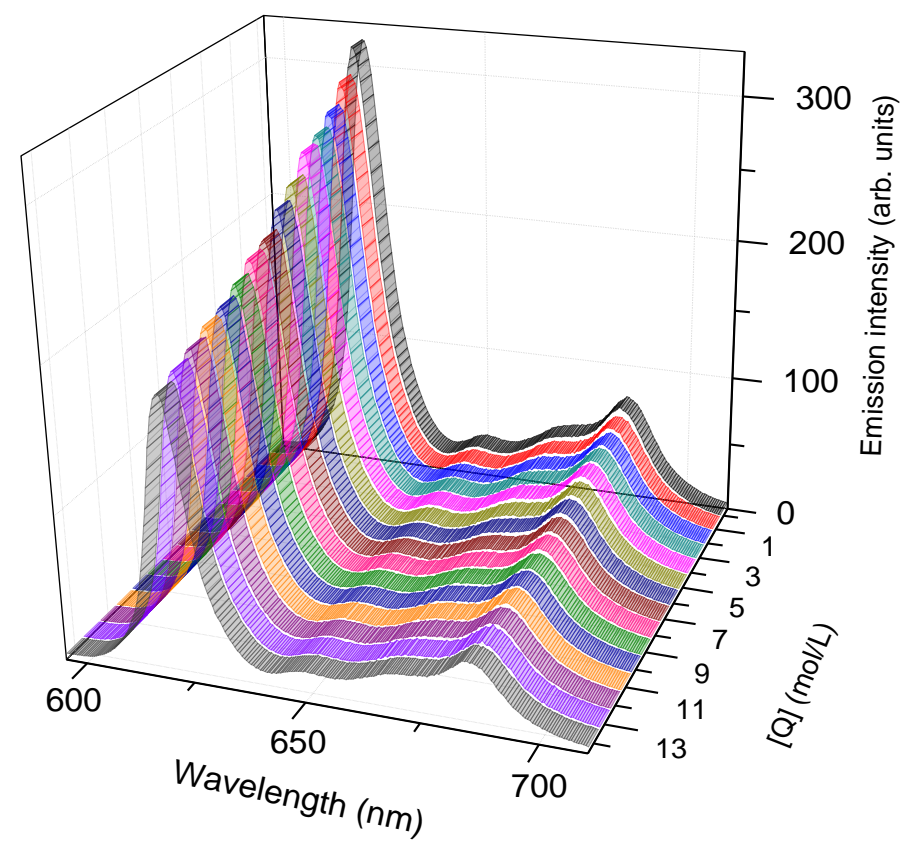

Figure S1. Steady state photoluminescence spectra of a mixture of OEP (concentration $=3.9 \times 10^{-6} \mathrm{~mol} / \mathrm{L}$ ) and $2 \mathrm{NF}$ in ACN liquid solution at $300 \mathrm{~K}\left(\lambda_{\mathrm{ex}}=564 \mathrm{~nm}\right)$. Concentration of $2 \mathrm{NF}(\mathrm{mol} / \mathrm{L}):(0) 0 ;(1) 6.3 \times 10^{-4} ;(2) 1.2 \times 10^{-3}(3)$ $1.7 \times 10^{-3}$; (4) $2.1 \times 10^{-3}$; (5) $2.6 \times 10^{-3}$ (6) $3.2 \times 10^{-3}$; (7) $3.8 \times 10^{-3}$; (8) $4.3 \times 10^{-3}$; (9) $4.9 \times 10^{-3}$; (10) $5.4 \times 10^{-3}$; (11) $5.8 \times 10^{-}$ ${ }^{3}(12) 6.2 \times 10^{-3} ;(13) 6.6 \times 10^{-3}(14) 6.9 \times 10^{-3}$. All the spectra are modified from inner filter effect.

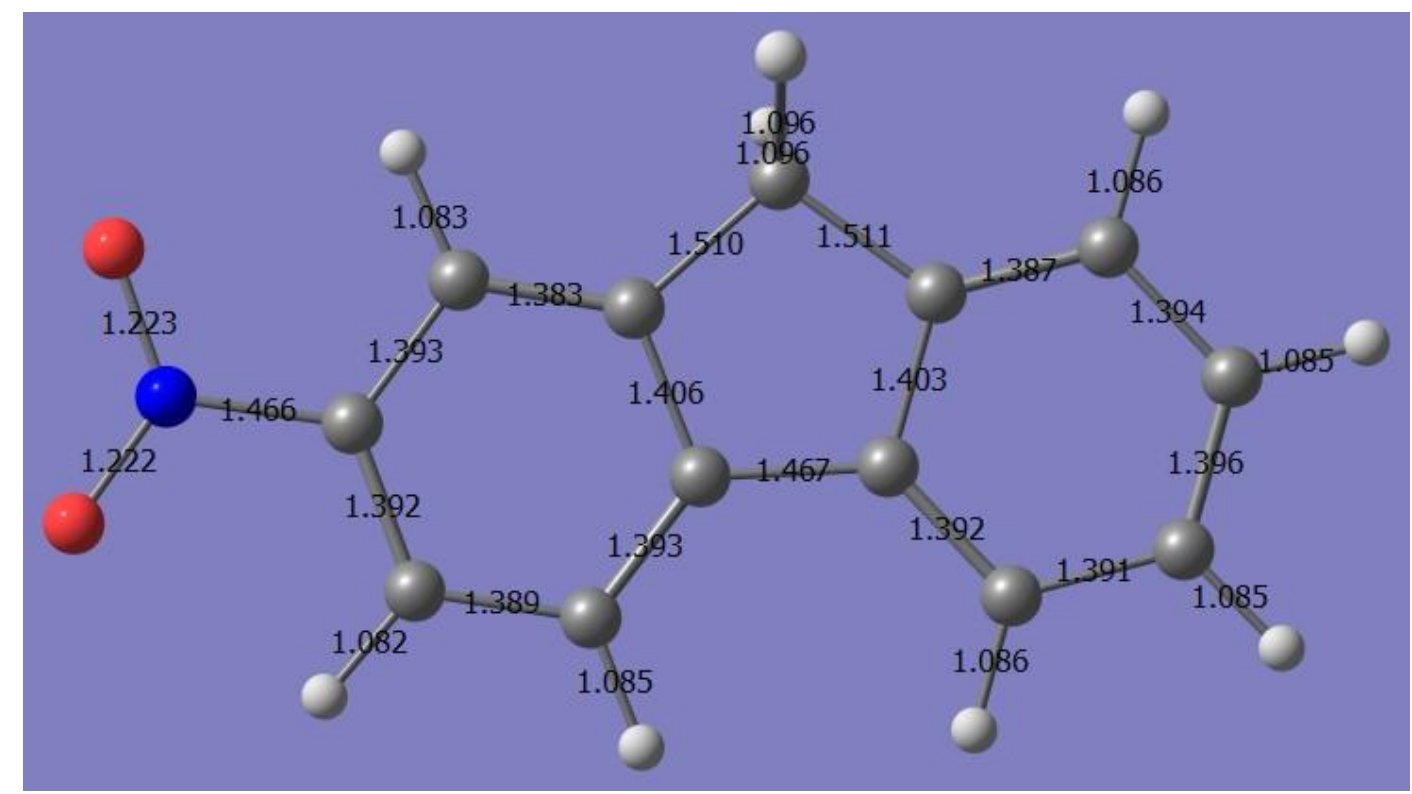

Figure S2. Geometrical parameter and Coordinates of Acceptor 


$\begin{array}{rr}0.93162800 & -2.43851300 \\ -1.87778200 & 1.41199300 \\ -2.36142300 & 0.10697800 \\ -1.52853200 & -1.00911600 \\ -0.16410600 & -0.78568000 \\ 0.34804200 & 0.52374900 \\ -0.50536600 & 1.62421500 \\ -2.58178400 & 2.23412700 \\ -1.96213000 & -2.00172600 \\ -0.11202500 & 2.63539700 \\ 0.96598900 & -1.78717200 \\ 0.93157000 & -2.43847600 \\ 2.18999200 & -0.90184600 \\ 3.53177000 & -1.25436300 \\ 4.49235600 & -0.24416200 \\ 4.11627900 & 1.10037400 \\ 2.77200900 & 1.45873200 \\ 1.81350600 & 0.44982700 \\ 3.83246000 & -2.29788200 \\ 5.54596700 & -0.50468400 \\ 4.87953000 & 1.87153300 \\ 2.48136200 & 2.50493800 \\ -3.81252200 & -0.10422100 \\ -4.21871400 & -1.25730000 \\ -4.53320300 & 0.88275800\end{array}$

-0.88093200
-0.00007800
-0.00007800
-0.00003300
0.00001300
0.00001000
-0.00003400
-0.00011200
-0.00003500
-0.00003400
0.00007000
0.88109700
0.00009400
0.00014500
0.00015900
0.00012400
0.00007400
0.00006000
0.00017300
0.00020200
0.00013500
0.00004500
-0.00012800
-0.00016800
-0.00018200

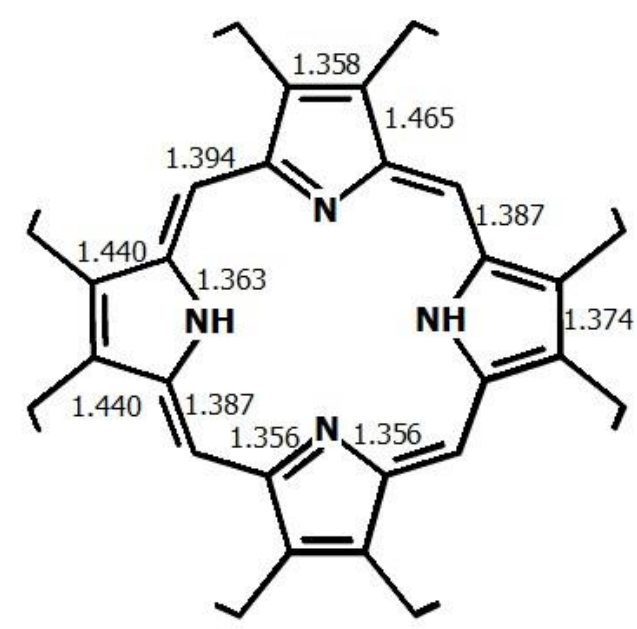

Figure S3. Geometrical parameters and Coordinates of Donor

N

C
C
C
C
2.10077600

2.88144300

4.25290100

4.24865200

2.87451800
-0.00639000
1.11142500
0.67384700
-0.69990700
-1.12900600

$-0.39909800$

$-0.39499200$

$-0.38446900$

$-0.38432700$

$-0.39491700$ 
$-0.39635900$

$-0.39619400$

$-0.38771800$

$-0.39791000$

$-0.38784200$

$-0.36699000$

$-0.36692000$

$-0.39792500$

$-0.38775800$

$-0.36696100$

$-0.36700500$

$-0.38784200$

$-0.39638700$

$-0.39625500$

$-0.39913800$

$-0.39503800$

$-0.38454300$

$-0.38440900$

$-0.39497800$

$-0.39828200$

$-0.39831800$

$-0.39809400$

$-0.39801500$

$-0.41186700$

$-0.41184400$

$-0.29741700$

1.11448000

$-0.63344900$

$-0.99767500$

1.13096400

1.81732900

1.47842800

$-0.29738400$

1.11437600

$-0.99799500$

$-0.63295600$

1.13084200

1.47788300

1.81759600

$-0.32246100$

1.09166200

$-0.67844400$

$-1.01162100$

1.10291400

1.78547800

1.46863400

$-0.32278800$

1.09099500

$-1.01275200$

$-0.67783400$

1.10209000

1.46701500

1.78567100

$-0.29741300$

1.11447300

$-0.63342300$

$-0.99769300$ 


$\begin{array}{lrrr}\text { H } & -2.89396400 & -6.47863800 & 1.13094800 \\ \mathrm{H} & -1.38134900 & -5.85641600 & 1.81734500 \\ \mathrm{H} & -2.71141600 & -4.74915300 & 1.47839700 \\ \mathrm{C} & 1.60095500 & -5.42275900 & -0.29732000 \\ \mathrm{C} & 2.15704700 & -5.65323600 & 1.11445400 \\ \mathrm{H} & 2.43182900 & -5.27597700 & -0.99791000 \\ \mathrm{H} & 1.08241800 & -6.32701200 & -0.63290500 \\ \mathrm{H} & 2.85460900 & -6.49590500 & 1.13093500 \\ \mathrm{H} & 2.68291200 & -4.76523200 & 1.47797400 \\ \mathrm{H} & 1.34611100 & -5.86411100 & 1.81765400 \\ \mathrm{C} & 5.42074100 & -1.63227500 & -0.32235300 \\ \mathrm{C} & 5.66954400 & -2.17334700 & 1.09177600 \\ \mathrm{H} & 6.31829600 & -1.11689200 & -0.67832500 \\ \mathrm{H} & 5.26006100 & -2.46934100 & -1.01151200 \\ \mathrm{H} & 6.51348400 & -2.86906500 & 1.10304500 \\ \mathrm{H} & 5.88830900 & -1.35648600 & 1.78559200 \\ \mathrm{H} & 4.78666600 & -2.69801800 & 1.46873600 \\ \mathrm{C} & 5.43073900 & 1.59895500 & -0.32270100 \\ \mathrm{C} & 5.68218300 & 2.13973200 & 1.09107800 \\ \mathrm{H} & 5.27565400 & 2.43639900 & -1.01268400 \\ \mathrm{H} & 6.32525200 & 1.07765500 & -0.67771500 \\ \mathrm{H} & 6.53054900 & 2.83005100 & 1.10218100 \\ \mathrm{H} & 4.80247400 & 2.67039000 & 1.46706500 \\ \mathrm{H} & 5.89532500 & 1.32213500 & 1.78577600\end{array}$

\section{Coordinates of Donor-Acceptor Complex}

$\begin{array}{lrrr}\mathrm{H} & 0.70676300 & -2.91039400 & 1.44232900 \\ \mathrm{C} & -2.03614500 & 1.07495500 & 1.89808100 \\ \mathrm{C} & -2.56338900 & -0.20818900 & 2.01277000 \\ \mathrm{C} & -1.77053900 & -1.35085300 & 2.10882400 \\ \mathrm{C} & -0.40034400 & -1.17240800 & 2.11376300 \\ \mathrm{C} & 0.15186900 & 0.11589000 & 2.00236400 \\ \mathrm{C} & -0.65971000 & 1.23901400 & 1.88116100 \\ \mathrm{H} & -2.70538100 & 1.92105100 & 1.81612200 \\ \mathrm{H} & -2.23591700 & -2.32533600 & 2.18996100 \\ \mathrm{H} & -0.23240400 & 2.22975700 & 1.77181200 \\ \mathrm{C} & 0.69650100 & -2.19632600 & 2.27256400 \\ \mathrm{H} & 0.58483900 & -2.77059700 & 3.19942900 \\ \mathrm{C} & 1.94052500 & -1.34308300 & 2.28098900 \\ \mathrm{C} & 3.26348700 & -1.71834400 & 2.45798300 \\ \mathrm{C} & 4.24842900 & -0.73253600 & 2.44894500 \\ \mathrm{C} & 3.91384400 & 0.61050600 & 2.26179300 \\ \mathrm{C} & 2.58993400 & 0.99219300 & 2.08388700 \\ \mathrm{C} & 1.60847400 & 0.00670800 & 2.09984300 \\ \mathrm{H} & 3.52852200 & -2.76054900 & 2.60563600 \\ \mathrm{H} & 5.28853200 & -1.00931700 & 2.59428900 \\ \mathrm{H} & 4.69466600 & 1.36314900 & 2.25519200 \\ \mathrm{H} & 2.33258600 & 2.03498600 & 1.92452800 \\ \mathrm{~N} & -4.01268700 & -0.35986800 & 2.06105600 \\ \mathrm{O} & -4.47242400 & -1.49293800 & 2.12699300 \\ \mathrm{O} & -4.70021100 & 0.65340400 & 2.05002600 \\ \mathrm{~N} & 1.94813600 & 1.11779600 & -1.13771600 \\ \mathrm{C} & 2.11854600 & 2.46417500 & -1.01851000 \\ \mathrm{C} & 3.53286000 & 2.72060600 & -1.08598500 \\ & & & \end{array}$


4.16554900

3.15330100

1.09792100

3. 33862600

2. 34892800

1.01583000

0.43222900

1.42879800

2.63580600

$-0.84932300$

$-2.18292300$

$-2.48214300$

$-1.27934400$

$-0.27443700$

$-0.94217000$

$-3.17085800$

$-1.78351000$

$-1.95579200$

$-3.36592700$

$-3.99473100$

$-2.98445600$

1.41422500

$-1.26331300$

$-4.19811600$

4.36639400

$-0.89523400$

1.05517400

$-0.99269300$

$-0.65960500$

$-1.85830700$

$-0.16227300$

$-0.46153400$

$-1.49095100$

0.22356800

$-3.85458100$

$-4.50394600$

$-4.49808100$

$-3.80034700$

$-5.49510600$

$-4.61441000$

$-3.88849200$

$-5.44758700$

$-6.26216400$

$-5.88525900$

$-5.52801500$

$-7.31331800$

$-6.20256200$

$-5.88717300$

$-3.98021000$

$-4.06462900$

$-3.40270200$

$-4.98457300$

$-4.53686000$

$-3.06680300$

$-4.64181100$

1.13260800

0.77285400
1.51496700

0.49414800

3.39739700

$-0.87935200$

$-1.85538500$

$-1.61072200$

$-2.83292100$

$-3.90680700$

$-3.29030400$

1. 95119200

2.19167700

3.60807700

4.21642700

3. 16014100

$-3.07055700$

1.22179500

$-0.77867500$

$-2.12951000$

$-2.38514500$

$-1.17359600$

$-0.15116400$

4.42785300

$-4.10692900$

1.56384100

$-1.21871300$

$-0.29982900$

0.63811300

5.64746200

5.84485400

6.26543200

6.01867800

6.89712600

5.51075600

5.26311700

4.20031700

3. 95182700

3.79148200

5.27825300

4.41123500

2. 88189800

4.37824100

$-0.91090900$

$-0.53483000$

$-1.80016200$

$-0.11267300$

$-0.38235100$

$-1.31615600$

0.38359200

$-3.75099400$

$-4.30889300$

$-4.43588400$

$-3.71051600$

$-5.29544200$

$-4.40705400$

$-3.63911700$

$-5.36970600$

$-5.76531000$
$-1.27197000$

$-1.26488300$

$-0.89023300$

$-1.30849600$

$-1.22377600$

$-1.14938000$

$-1.10377100$

$-1.11189000$

$-1.20964000$

$-1.16968100$

$-1.20038700$

$-0.98162800$

$-0.81143400$

$-0.95200700$

$-1.10843700$

$-1.37283500$

$-1.23746200$

$-1.20289900$

$-1.35000500$

$-1.49804300$

$-1.39179500$

$-0.76251500$

$-1.09137000$

$-1.44473000$

$-1.38678000$

$-1.14417500$

$-1.12382800$

$-0.47396900$

1.01126300

$-0.73442700$

$-1.08666000$

1.23529400

1.63913700

1.29462600

$-0.87894500$

0.48951300

$-1.66708300$

$-1.06434400$

0.54457000

0.69000200

1.28817500

$-1.76773500$

$-0.52595100$

$-2.23287800$

$-2.51479900$

$-0.78712100$

0.23527900

$-0.06814000$

$-1.30784900$

0.11931100

$-1.93994700$

$-1.74018700$

0.12498000

0.55912400

0.76104700

$-0.98064400$

0.45832200 


$\begin{array}{rrrr}\mathrm{H} & 2.00245100 & -5.94978900 & -1.30574800 \\ \mathrm{H} & 0.31296000 & -5.65139200 & -1.65233900 \\ \mathrm{H} & 0.58435800 & -6.83967400 & 0.53985600 \\ \mathrm{H} & 1.58782000 & -5.50726600 & 1.14187100 \\ \mathrm{H} & -0.12348300 & -5.23654600 & 0.79830300 \\ \mathrm{C} & 3.99974100 & -3.90709700 & -1.28990900 \\ \mathrm{C} & 4.74968000 & -3.91024100 & 0.04727800 \\ \mathrm{H} & 4.59758900 & -3.37339200 & -2.03830100 \\ \mathrm{H} & 3.91167500 & -4.93505100 & -1.65702000 \\ \mathrm{H} & 5.73702500 & -4.36966200 & -0.05792200 \\ \mathrm{H} & 4.87832400 & -2.89193300 & 0.42528500 \\ \mathrm{H} & 4.18841000 & -4.47350500 & 0.79944800 \\ \mathrm{C} & 5.63026800 & 1.26113600 & -1.47615600 \\ \mathrm{C} & 6.39187100 & 0.88881100 & -0.20008100 \\ \mathrm{H} & 6.08701500 & 2.15090100 & -1.92210500 \\ \mathrm{H} & 5.75191300 & 0.46181500 & -2.21580400 \\ \mathrm{H} & 7.44531400 & 0.69307500 & -0.42006000 \\ \mathrm{H} & 6.34378300 & 1.70032400 & 0.53214000 \\ \mathrm{H} & 5.96187600 & -0.00302500 & 0.26355600 \\ \mathrm{C} & 4.15571700 & 4.07338400 & -0.92415900 \\ \mathrm{C} & 4.23483400 & 4.49961500 & 0.54803000 \\ \mathrm{H} & 3.5858900 & 4.81800300 & -1.49131800 \\ \mathrm{H} & 5.16204600 & 4.06673400 & -1.35467300 \\ \mathrm{H} & 4.70339300 & 5.48249200 & 0.65099500 \\ \mathrm{H} & 3.23699300 & 4.54982700 & 0.99492600 \\ \mathrm{H} & 4.82101000 & 3.77902100 & 1.12650200 \\ & & & \end{array}$

